\title{
TANASE: CONCEITOS, PRODUÇÃO E APLICAÇÃO
}

\author{
GUSTAVO ADOLFO SAAVEDRA PINTO* \\ SONIA COURI** \\ SELMA GOMES FERREIRA LEITE*** \\ EDY SOUSA DE BRITO*
}

\begin{abstract}
O objetivo deste trabalho foi efetuar revisão do conhecimento sobre tanase, apontando necessidades e perspectivas de utilização, em especial para a área de alimentos. Foram enfatizados tópicos como importância fisiológica da tanase e seu mecanismo de ação, sua produção por microrganismos, os métodos analíticos para sua determinação, a sua produção por fermentação, a regulação da biosíntese, suas características e propriedades, a imobilização e suas aplicações. A principal aplicação dessa enzima encontra-se na produção de chás instantâneos, porém outros campos potenciais podem ser vislumbrados como sua utilização para elaboração de rações animais com maior valor nutricional, produção de compostos antioxidantes e produção de ácido gálico.
\end{abstract}

PALAVRAS-CHAVE: TANASE - PRODUÇÃO; INDÚSTRIA DE ALIMENTOS.

\section{INTRODUÇÃO}

Os taninos representam o quarto mais abundante constituinte vegetal, depois da celulose, da hemicelulose e da lignina. Atuam como parte do mecanismo de defesa dos vegetais contra microrganismos, herbívoros e condições ambientais hostis. As plantas que contêm altos níveis de taninos apresentam vantagem evolucionária significativa sobre seus predadores e outras espécies vegetais, que competem pelo mesmo nicho. Altas quantidades de taninos estão associadas com a resistência de vegetais ao ataque microbiano (SCALBERT, 1991).

* Pesquisadores, Embrapa Agroindústria Tropical - Fortaleza/CE (e-mail: gustavo@cnpat.embrapa.br).

** Pesquisadora, Embrapa Agroindústria de Alimentos - Rio de Janeiro/RJ (e-mail: scoury@ctaa.embrapa.br).

Professora, Escola de Química, Universidade Federal do Rio de Janeiro - Rio de Janeiro/RJ. 
A palavra tanino traz consigo diferentes definições, particularmente no que se refere à literatura botânica. As implicações originais dessa palavra indicam claramente material vegetal utilizado na produção de couro (HASLAM e LILLEY, 1988; CANNAS, 2002 e BHAT, SINGH e SHARMA, 1998). As principais características dessa classe de compostos são: a massa molecular (que pode variar entre 0,5 a $20 \mathrm{KDa}$ ); a solubilidade em água (observada exceto no caso daqueles com elevado peso molecular); a habilidade de ligar-se a proteínas e formar complexos (na maioria das vezes insolúveis); e a capacidade de combinação com celulose e pectina para formar complexos insolúveis (McLEOD, 1974 e MUELLER-HARVEY e REED, 1992). Os taninos foram divididos em dois grupos com base na estrutura molecular: os taninos hidrolisáveis e as proantocianidinas, originalmente chamadas de taninos condensados (DESHPANDE, CHERYAN e SALUNKHE, 1984; HASLAM e LILLEY, 1988; LEKHA e LONSANE, 1997; BHAT, SINGH e SHARMA, 1998).

Os taninos hidrolisáveis são poliésteres de ácido gálico e diferentes carboidratos (McSWEENEY et al. 2001; BRUYNE et al. 1999). A molécula com um poliol, em geral glicose, compõe o núcleo central, cujos radicais hidroxil podem estar parcial ou totalmente esterificados com radicais galoil. Esses taninos são hidrolisados por ácidos, bases e enzimas (ex.: tanase) em suas unidades formadoras (CANNAS, 2002), sendo divididos em galotaninos e elagitaninos. Nos galotaninos, os grupos fenólicos que esterificam o núcleo glicosídico são constituídos pelo ácido gálico (ou radical galoil), ou pelo ácido digálico, estando as duas unidades galoil unidas por ligação depsídica (Figura 1). As moléculas são usualmente compostas pelo núcleo de glicose e 6 a 9 grupos galoil. Apresentam massas moleculares em torno de $3 \mathrm{KDa}$. Há grande abundância de ésteres de glicose mono ou di-galoil na natureza, que não são considerados taninos. É necessário que pelo menos 3 grupos hidroxil da molécula de glicose estejam esterificados para exibir a capacidade de se ligar e precipitar proteínas para serem considerados taninos. O mais comum dos galotaninos é o ácido tânico (Figura 2), obtido a partir de galhas de Rhus semialata. Nos elagitaninos, os grupos fenólicos utilizados são moléculas de ácido hexahidroxidifênico que podem se desidratar espontaneamente para formar sua dilactona estável, o ácido elágico (Figura 1). Os elagitaninos apresentam massa molecular entre 2 e $5 \mathrm{KDa}$ (CANNAS, 2002).

As proantocianidinas são mais vastamente distribuídas no reino vegetal que os taninos hidrolisáveis. Ainda são chamadas de taninos condensados devido a sua estrutura química compacta. Contudo, o termo pode ser 
potencialmente confuso, pois são os taninos hidrolizáveis que sofrem reações de condensação durante sua síntese. As proantocianidinas resultam do acoplamento de uma unidade flavonil eletrofílica, gerada a partir de um flavan-4-ol ou de um flavan-3,4-diol, uma unidade flavanil nucleofílica. Desta forma, são oligômeros ou polímeros de unidades flavonóides, como a catequina (Figura 1), unidas por ligações carbonocarbono não suscetíveis à clivagem por hidrólise. Ao contrário dos taninos hidrolisáveis, proantocianidinas não contém resíduos de carboidratos (DESHPANDE, CHERYAN e SALUNKHE, 1984). Contém de 2 a 50 ou mais unidades flavonóides, podendo atingir massas moleculares superiores a $20 \mathrm{KDa}$. As proantocianidinas apresentam grande variedade estrutural devido ao número de grupos hidroxilas presentes em cada unidade, à estereoquímica dos três centros quirais do anel $\mathrm{B}$, à localização das ligações interflavana e (em menor proporção) a possíveis derivatizações como $O$-metilalação ou $C$-e $O$-glicosilações (BRUYNE, 1999). Em razão de suas estruturas químicas, sem a presença de ligações éster e depsídica, as proantocianidinas não são suscetíveis a hidrólise pela tanase.

O objetivo deste trabalho foi efeturar revisão do conhecimento sobre tanase, apontando necessidades e perspectivas de utilização, em especial para a área de alimentos.

\section{FIGURA 1 - ESTRUTURAS DO ÁCIDO GÁLICO (A), DE SEU DÍMERO, O ÁCIDO DIGÁLICO (B), DO ÁCIDO ELÁGICO (C) E DA CATEQUINA (D)}

(A)

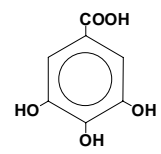

(C)

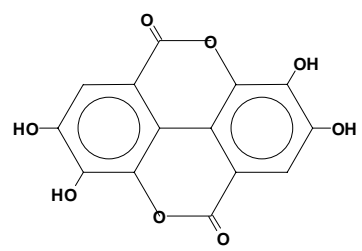

(B)

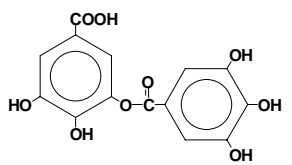

(D)

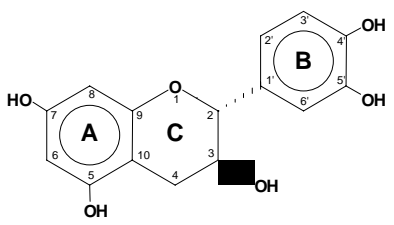

Adaptado de PINTO (2003). 


\section{FIGURA 2 - ESTRUTURA DO ÁCIDO TÂNICO - $\mathbf{R}_{1}$ : ÁCIDO GÁLICO E $R_{2}$ : ÁCIDO DIGÁLICO}

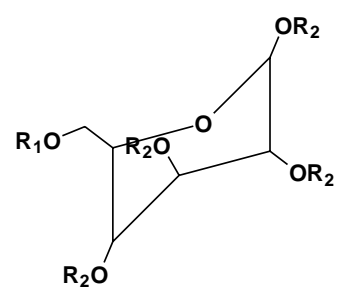

Adaptado de PINTO (2003).

\section{IMPORTÂNCIA FISIOLÓGICA E MODO DE AÇÃO DA TANASE}

Se os taninos são parte do sistema de defesa vegetal contra os microrganismos, a produção de tanase pode ser considerada como parte do contra-ataque microbiano. Tal ataque inclui estratégias como a secreção de substâncias com elevada afinidade por taninos, a produção de enzimas resistentes aos taninos, a produção de polifenoloxidases (enzimas capazes de quebrar os anéis fenólicos das proantocianidinas) e a produção de sideróforos (SCALBERT, 1991).

A tanase atua na invasão da planta hospedeira pela hidrólise de parte dos compostos fenólicos presentes em tecidos vivos ou em decomposição, mais especificamente os taninos hidrolisáveis (SCALBERT, 1991). Diferentes estudos relatados por LEKHA e LONSANE (1997) apontam que microrganismos de solo produtores de tanase desempenham papel ativo na decomposição e reciclagem de materiais vegetais ricos em taninos. Assim, as espécies microbianas que sintetizam esta enzima apresentam vantagem competitiva às demais de determinado "habitat".

A decomposição de taninos hidrolisáveis é mediada por duas enzimas. Uma com atividade esterásica sobre a ligação éster entre o grupo anel aromático e o resíduo de glicose, e a outra depsidásica sobre a ligação éster entre os anéis aromáticos. HASLAM e STRAGROOM (1966) responsabilizaram a tanase pelas duas atividades. Também relataram que a proporção entre essas duas atividades podia variar de acordo com as condições de cultivo. BEVERINI e METCHE (1990), utilizando colunas de afinidade, fracionaram duas isoformas de tanase fúngica. Ambas com as duas atividades, sendo que a tanase I apresentou maior característica esterásica e a tanase II atividade depsídica mais pronunciada. 
A Figura 3 mostra modelos propostos para a degradação do ácido tânico pela tanase. Na primeira etapa a enzima hidrolisa todas as ligações depsídicas, liberando 1,2,3,4,6-pentagaloilglicose e ácido gálico. Em seguida, os demais resíduos galoil são seqüencialmente removidos até a completa liberação da molécula de glicose (LEKHA e LONSANE, 1997).

FIGURA 3 - MODELOS PROPOSTOS DE AÇÃO DA TANASE - (A): HIDRÓLISE COMPLETA DO ÁCIDO TÂNICO, $R_{1}=$ ÁCIDO GÁLICO E R = ÁCIDO DIGÁLICO - (B): HIDRÓLISE DO GALATO DE EPICATEQUINA
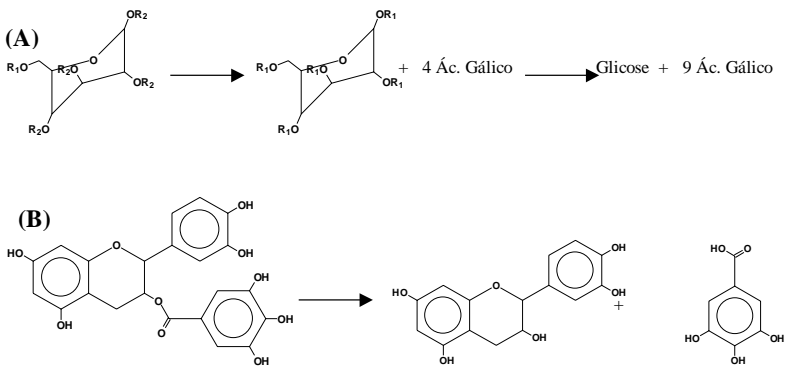

Adaptado de LEKHA e LONSANE (1997).

A tanase também pode atuar sobre substratos como o ácido clorogênico ou galato de catequina e epigalocatequina-3-galato. GARCIA-CONESA et al. (2001) desenvolveram modelo de hidrólise dessa classe de substâncias no qual há a liberação de uma molécula de ácido gálico e uma de proantocianidina (Figura 3).

Tanases também apresentam atividade hidrolítica sobre ésteres de diferulatos, embora sua eficiência seja menor que a da cinamoil esterase. Desta forma, as tanases podem contribuir para a degradação da parede celular dos vegetais, já que seriam capazes de romper ligações cruzadas existentes entre as diferentes macromoléculas que a compõe (GARCIACONESA et al., 2001).

De forma similar a outras esterases, a tanase em meio aquoso catalisa predominantemente reações hidrolíticas. Entretanto, em meios orgânicos com teores reduzidos ou nulos de água as reações de esterificação passam a ser predominantes (TEWARI et al., 1996) para o equilíbrio entre o ácido gálico e o propilgalato (Figura 4). 


\title{
FIGURA 4 - CONVERSÃO DE PROPILGALATO EM ÁCIDO GÁLICO PELA TANASE EM FUNÇÃO DO MEIO REACIONAL
}

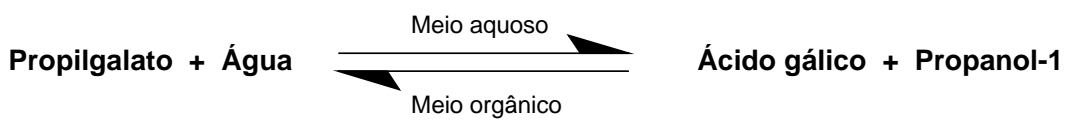

\section{PRODUÇÃO DE TANASE POR MICRORGANISMOS}

Diferentes organismos, como bactérias (MONDAL e PATI, 2000 e OSAWA et al., 2000), leveduras (AOKl et al., 1976), fungos filamentosos (BRADOO, GUPTA e SAXENA, 1996; BAJPAI e PALTI, 1996 e PINTO et al., 2001) e plantas (NIEHAUS e GROSS, 1997) são considerados capazes de sintetizar tanases.

DESCHAMPS, OTUK e LEBEUALT (1983) isolaram linhagens bacterianas capazes de degradar o ácido tânico e compostos correlatos de casca de pinheiro e de carvalho em apodrecimento. SKENE e BROOKER (1995), NEMOTO et al. (1995) e NELSON et al. (1995) detectaram atividade de tanase em bactérias anaeróbicas presentes no rumem de animais com dietas ricas em taninos. AJAY KUMAR, GUNASEKARAN e LAKSHMANAN (1999) isolaram de efluentes de curtumes, uma linhagem de Citrobacter freundii capaz de degradar e utilizar o ácido tânico como única fonte de carbono.

Grupo liderado por OSAWA, da Universidade de Kobe (Japão), vem isolando bactérias capazes de produzir tanases a partir de alimentos fermentados e de fezes (humanas, e de ratos silvestres). Utilizando testes bioquímicos e de biologia molecular, diferentes espécies de Lactobacillus foram identificadas com possibilidade de ocorrência de novas espécies. Também foram detectados cocos gram-positivos, identificados como Streptococcus gallolyticus (OSAWA et al., 2000; NISHITANI et al., 2004 e SASAKI et al., 2005).

VAQUERO, MARCOBAL e MUÑOZ et al. (2004) analisaram diferentes bactérias láticas isoladas de mosto de uva ou vinhos de diferentes regiões da Espanha. Dentre todas as espécies dos gêneros Lactobacillus, Leuconostoc, Oenococcus ou Pediococcus, somente as linhagens identificadas como Lactobacillus plantarum produziram tanase. Sugeriam que a atividade de tanase pode ser considerada como critério de seleção de culturas "starter" maloláticas, uma vez que poderiam conferir vantagens no processo de vinificação pela redução da adstringência e turbidez do vinho. 
AOKI, SHINKE e NISHIRA (1976) isolaram várias linhagens de levedura produtoras de tanase a partir de solo. A linhagem identificada como Candida sp. K1, na presença de ácido tânico, produz tanase intra e extracelular. Contudo, são os fungos filamentosos e mais especificamente as espécies dos gêneros Aspergillus e Penicillium, os melhores produtores de tanase (BRADOO et al., 1996; BAJPAI e PALTI 1996; BHAT, SIGH e SHARMA, 1998 e BATRA e SAXENA, 2005). Das 80 linhagens fúngicas isoladas por YAMADA et al. (1968) como produtoras de tanase, as duas que apresentaram maior capacidade de síntese foram identificadas como Aspergillus oryzae. Diferentes linhagens de Aspergillus niger, $A$. japonicus e $A$. oryzae são citadas como as melhores produtoras de tanase. Linhagens do gênero Penicillium também sintetizam elevadas quantidades de tanase, porém não tanto quanto as espécies de Aspergillus (GANGA, NANDY e SANTAPPA, 1978; LEKHA e LONSANE, 1997; BRADDO, GUPTA e SAXENA, 1996, BHAT, SINGH e SHARMA, 1998 e PINTO et al., 2001).

Apesar de vários microrganismos produzirem tanases, essas não são igualmente ativas com todos os taninos hidrolisáveis. As tanases de levedura são efetivas somente na decomposição do ácido tânico (galotanino), enquanto as enzimas bacterianas e fúngicas são eficientes na degradação de ácido tânico e outros taninos hidrolisáveis que ocorrem na natureza (BHAT, SINGH e SHARMA, 1998).

\section{MÉTODOS ANALÍTICOS PARA DETERMINAÇÃO DE TANASE}

Os primeiros métodos analíticos para a determinação de tanase foram baseados na titulação do ácido gálico liberado após a hidrólise do ácido tânico pela enzima. A dificuldade na observação do ponto de viragem do indicador diminui a precisão desses métodos (LEKHA e LONSANE, 1997).

IIBUCHI, MONIDA e YAMADA (1967) descreveram método espectrofotométrico que acompanha a redução dos valores de absorvância a $310 \mathrm{~nm}$, devido ao rompimento das ligações éster e depsídicas presentes nas moléculas de ácido tânico. Trata-se de método simples e de fácil execução, sendo empregado em sua forma original (LEKHA, RAMAKRISHNA e LONSANE, 1993) ou com modificações como a proposta por SANDERSON et al. (1974). Contudo, o método de libuchi e seus similares apresentam dois fortes pontos negativos que diminuem sua acurácia. Não havendo curva-padrão que correlacione os valores de absorvância com a faixa de concentração de ácido gálico, a unidade de 
atividade não é expressa no sistema internacional. A unidade é definida como a quantidade de enzima que reduz a absorvância da solução de substrato em 0,001 por minuto de reação. Além disso, a solução de substrato apresenta elevados valores de absorvância (superiores 0,500) e a diferença é muito pequena após a adição da enzima.

HASLAM e TANNER (1970), críticos severos do método de libuchi, desenvolveram ensaio espectrofotométrico na região do visível que utiliza o éster $p$-nitrofenil galato como substrato análogo. Contudo, a nãodisponibilidade comercial desse substrato resultou em pouca aceitação do método (SHARMA et al, 2000).

JEAN et al. (1981) propuseram a utilização de cromatografia a gás (CG), enquanto BEVERINI e METCHE (1990), BARTHOMEUF, REGERAT e POURRAT (1993) e AGUILAR et al. (1999) sugeriram o uso de cromatografia a líquido de alta eficiência (CLAE) para detecção do ácido gálico liberado pela enzima. Esses métodos, embora específicos e de alta precisão e reprodutibilidade, requerem instrumentação sofisticada, o que limita sua utilização (SHARMA, BHAT e DWARA, 2000).

INOUE e HAGERMAN (1988) relataram método para determinação de galotaninos, que envolve a formação de complexo entre a rodanina e o ácido gálico liberado após a hidrólise ácida do tanino. O complexo, que apresenta absorvância máxima a $520 \mathrm{~nm}$, resulta da reação da rodanina com os grupos hidroxílicos vicinais do ácido gálico. As moléculas de rodanina que não reagiram não apresentam, em solução básica, absorvâncias em comprimentos de onda superiores a $450 \mathrm{~nm}$. A rodanina apresenta baixa ou nenhuma afinidade pelos grupos hidroxílicos de radicais galoil presentes na estrutura dos taninos. A rodanina também pode reagir em soluções alcalinas, com quinonas ou hidroquinonas, mas os produtos dessas reações absorvem comprimentos de onda maiores (THIES e FISCHER, 1973). Esse método torna-se muito útil para análises rotineiras, pois apresenta alta especificidade (sem interferência dos compostos vegetais fenólicos), sensibilidade e precisão. O método de rodanina foi posteriormente adaptado por SKENE e BROOKER (1995) e SHARMA, BHAT e DAWRA (2000) para determinação da atividade de tanase produzida por bactérias e por fungos, respectivamente.

NISHITANI e OSAWA (2003) desenvolveram metodologia capaz de determinar valores da ordem de 0,63 a $10 \mathrm{mU} / \mathrm{mL}$. Sua sensibilidade é superior aos métodos espectrofotométricos de IIBUCHI, MONIDA e YAMADA (1967) e de SHARMA et al. (2000) em três ordens de grandeza. 
Como desvantagem, o método dura 24 horas ao invés dos 10 minutos dos métodos tradicionais. NISHITANI e OSAWA (2003) afirmaram os métodos mais sensíveis têm grande aplicação na quantificação da atividade de tanase em isolados bacterianos degradadores de taninos da microflora intestinal de animais, uma vez que esses compostos exercem importante papel na sua alimentação.

\section{PRODUÇÃO DE TANASE POR FERMENTAÇÃO}

Poucos trabalhos tratam da produção de tanase por fermentação líquida em superfície. As pesquisas que utilizam esse tipo de processo abordam a localização da enzima produzida. GANGA, NANCY e SANTAPPA (1977) testaram diferentes espécies de Aspergillus e diferentes meios de cultivo (Czapeck, Extrato de malte, Raulin neutro e Sabouraud). Todos os experimentos demonstraram que a atividade da tanase foi significativamente maior nos extratos celulares, indicando que a enzima seria preferencialmente intracelular. POURRAT et al. (1982) afirmaram que a razão entre as atividades observadas no meio e no micélio é influenciada pelo $\mathrm{pH}$ inicial do meio. Contudo, a atividade intracelular é pelo menos $200 \%$ superior a extracelular. LEKHA e LONSANE (1994) observaram que a enzima é completamente intracelular nas primeiras 48 horas de fermentação, sendo excretada após esse tempo sem ultrapassar a proporção 1:1. Outra similaridade entre esses trabalhos envolve 0 elevado tempo de fermentação, de 6 a 10 dias até a máxima produção da enzima, tornando essa fermentação inviável tecnicamente devido a baixa produtividade.

De acordo com a literatura consultada, a tanase é produzida na presença do indutor. Assim, a utilização do ácido tânico como indutor ou única fonte de carbono é fundamental (Tabela 1). Mesmo na presença de outras fontes de carbono a concentração de ácido tânico constitui o fator predominante na produção de tanase (YAMADA et al., 1968; GANGA, NANDY e SANTAPPA et al., 1977). Diferentes fontes de nitrogênio inorgânicas e orgânicas (por exemplo sulfato de amônio, nitrato de sódio e peptona) têm sido utilizadas para a produção da tanase. (YAMADA et al., 1968; DHAR e BOSE, 1964; AOKI, SHINKE e NISHIRA et al., 1968 e AGUILAR et al., 2001). Contudo, não se encontra estudo sistemático sobre qual delas é a mais adequada para a fermentação submersa. Em relação aos micronutrientes, LIPPITSCH (1961) observou que íons de ferro, zinco e cobre são essenciais para a produção da enzima. 


\section{TABELA 1 - FONTES DE CARBONO E TEMPERATURA UTILIZADAS PARA A SÍNTESE DE TANASE POR DIFERENTES FUNGOS FILAMENTOSOS EM FERMENTAÇÃO SUBMERSA}

\begin{tabular}{llccl}
\hline \multicolumn{1}{c}{ MICRORGANISMO } & FONTE DE CARBONO & $\begin{array}{c}\mathbf{C} \\
\mathbf{( g / \mathbf { L } )}\end{array}$ & $\begin{array}{c}\text { T } \\
\left({ }^{\circ} \mathbf{C}\right)\end{array}$ & REFERÊNCIA \\
\hline Aspergillus flavus & Ácido tânico & 1,0 & 30 & YAMADA et al., 1968 \\
Aspergillus niger & Ácido tânico & 20,0 & 28 & DHAR e BOSE, 1964 \\
& Sacarose & 30,0 & & \\
Penicillium chrysosporium & Ácido tânico & 20,0 & 28 & RAJKUMAR e NANDY, 1983 \\
& Sacarose & 20,0 & & \\
Aspergillus niger LCF8 & Extrato de tanino & -- & 33 & $\begin{array}{l}\text { BARTHOMEUF, REGERAT e } \\
\text { POURRAT, 1994 }\end{array}$ \\
Aspergillus awamori & Ácido tânico & $25,0-$ & 37 & SETH e CHAND, 2000 \\
& & 45,0 & & \\
\hline
\end{tabular}

$C=$ concentração / $T=$ temperatura .

Os valores iniciais de $\mathrm{pH}$ dos meios de produção de tanase variam de 3 a 7 . Contudo, em poucos dos artigos consultados foi verificado acompanhamento dos valores de $\mathrm{pH}$ durante a fermentação (GANGA, NANDY e SANTAPPA, 1977; SETH e CHAND, 2000 e AGUILAR et al., 2001).

A esterilização dos meios para produção de tanase tem como complicador o fato do ácido tânico ser termolábil. Desta forma, o mesmo é dissolvido e esterilizado por filtração e em seguida adicionado assepticamente ao restante do meio autoclavado (DESCHAMPS e LEULLIETTE, 1994).

NICOLSON et al. (1931) observaram que o rendimento de tanase aumentou quando foi utilizado fungo que cresceu por gerações assexuais sucessivas em meio contendo galotanino. Visando maximizar a síntese da enzima no meio de produção, AOKI et al. (1976) e SHARMA et al. (2001) adicionaram pequenas quantidades de ácido tânico aos meios de manutenção das linhagens produtoras de tanase.

Da mesma forma que na fermentação líquida em superfície, diferentes autores relatam que neste tipo de processo a maior fração de tanase localiza-se no espaço intracelular (RAJKUMAR e NANDY, 1983; BARTOMEUF, REGERAT e POURRAT, 1994; SETH e CHAND, 2000). A. niger PKL 104 produziu tanase intracelular nas primeiras 48 horas de processo e após esse tempo grande parte da enzima foi excretada, alcançando proporção de 1:6 (LEKHA e LONSANE, 1994). AGUILAR et al. (2001) observaram a presença da enzima nos dois espaços, contudo houve predominância da fração extracelular. 
O primeiro relato de produção de tanase por fermentação semi-sólida data de 1917, no qual uma linhagem de $A$. oryzae cresceu sobre farelo de trigo. Foi observada maior produção da enzima conforme aumento da concentração de tanino no meio. Contudo, a partir de $20 \%$ de tanino o crescimento do fungo foi inibido (LEKHA e LONSANE, 1997).

No final da década de 50 diferentes fungos foram testados em meio de farelo de trigo. Espécies de Aspergillus e Penicillium foram as que apresentaram os melhores resultados. Também foi observado que a tanase podia ser produzida por Penicillium spp. tendo ácido tânico ou ácido gálico como indutores, mas sua produção não foi correlacionada ao crescimento da linhagem (LEKHA e LONSANE, 1997).

Segundo LEKHA, RAMAKRISHNA e LOSANE et al. (1993) a linhagem A. niger PKL104, isolada de solo, apresentou boas características de produção. A síntese de tanase por essa linhagem também foi afetada pela concentração de ácido tânico utilizada, sendo sua produção relacionada com o crescimento do fungo (estimado por glicosamina). Em trabalhos subseqüentes, a produção foi otimizada utilizando metodologia de superfície de resposta. Os autores verificaram que a enzima produzida por fermentação semi-sólida era totalmente extracelular (LEKHA e LONSANE, 1993 e LEKHA e LONSANE, 1994).

A síntese de tanase por $A$. niger PKL104 foi avaliada mediante três diferentes processos fermentativos. A fermentação semi-sólida mostrouse 4,8 vezes mais eficiente na produção da enzima que a fermentação líquida em superfície e 2,5 vezes mais que a fermentação submersa. Além do aumento no rendimento, o processo semi-sólido apresentou o máximo de produtividade na metade do tempo (3 dias) observado nos demais processos (LEKHA e LONSANE, 1994).

PINTO (2003) utilizou A. niger 3T5B8, previamente selecionado (PINTO et al., 2001), para otimizar a produção de tanase em meio semi-sólido (composto de $84 \%$ de farelo de trigo, 15\% de ácido tânico e 1\% de sacarose), umidificado com solução contendo sulfato de amônio $\left(1,7 \%_{\mathrm{pv}}\right)$ e fosfato de sódio monobásico $\left(2,0 \%_{\mathrm{pv}}\right)$, obtendo $34,6 \mathrm{U} \cdot \mathrm{g}^{-1}$ ao final de 24 horas de fermentação.

AGUILAR et al. (2001) e LAGEMAAT e PYLE (2001) estudaram a produção de tanase empregando espuma de poliuretano como suporte inerte. AGUILAR et al. (2001) utilizaram linhagem de $A$. nigerem processo de batelada, no qual foram adicionados $6,5 \mathrm{~g}$ de meio contendo ácido 
tânico e $7 \times 10^{7}$ esporos em 3,5 g de espuma. Já LAGEMAAT e PYLE (2001) usaram linhagem de P. glabrum e desenvolveram fermentador semisólido contínuo em escala laboratorial, no qual o meio líquido contendo ácido tânico era injetado.

KAR, BANERJEE e BHATTACHARYYA (1999) propuseram processo semi-sólido modificado, utilizando reator cilíndrico encamisado, contendo sistema flutuador com lã de vidro em estrutura oca de polipropileno. A fermentação do substrato sólido inicia-se após a inoculação. Contudo, o meio líquido entra em contato com a fase sólida pela estrutura oca do flutuador, lixiviando o produto formado (ácido gálico). Pela abertura lateral, o meio pode ser retirado e recolocado sem perturbar o processo fermentativo.

\section{REGULAÇÃO DA BIOSSÍNTESE DA TANASE}

Existem três mecanismos regulatórios genéticos que afetam a síntese e secreção das enzimas. A indução (enzima somente é sintetizada na presença de seu substrato ou análogo), a repressão catabólica (a síntese da enzima é inibida quando fontes de carbono de rápida assimilação estão presentes) e a repressão por produto final (um metabólito final ou o próprio produto da enzima inibem sua síntese).

A síntese da tanase está vinculada à presença de indutor. $O$ ácido tânico e o seu produto de hidrólise, o ácido gálico, podem induzir a síntese da tanase, sendo o primeiro mais efetivo (KNUDSON, 1913). O indutor para síntese de tanase mais freqüentemente utilizado é o ácido tânico. Porém, trata-se de molécula com elevado peso molecular, carregada de grupos polares e com alta reatividade frente aos componentes da parede celular. Desta forma, sua absorção direta pelo microrganismo fica impossibilitada (LEKHA e LONSANE, 1997). SINGH e HAYASHI (1995) sugeriram que níveis basais de tanase seriam produzidos de forma constitutiva de modo que o ácido gálico (resultante da hidrólise do ácido tânico) poderia ser metabolizado e atuar como indutor. BRADOO, GUPTA e SAXENA (1996) relataram que a tanase foi produzida de forma constitutiva em fermentação submersa por $A$. japonicus. No entanto, o microrganismo duplicou a síntese de enzima pela presença de ácido tânico nos meios de cultura. BAJPAI e PALTI (1996) também observaram que A. fischerii MTCC150, Fusarium solani MTCC350 e Trichoderma viride MTCC167 produziam níveis basais de tanase, tanto intra como extracelular. Fato não observado para A. niger MTCC282. 
PINTO (2003) observou que A. niger 3T5B8 somente sintetizou tanase quando o meio de cultivo semi-sólido continha ácido tânico ou ácido gálico. Ambos compostos apresentaram níveis de indução similares, quando na mesma concentração.

KNUDSON (1913) observou que a adição de $10 \%$ de caldo-de-cana ao meio de cultura não afetou a síntese de tanase por $A$. niger, mas inibiu a secreção da enzima por Penicillium sp. BRADOO, GUPTA e SAXENA (1996) evidenciaram síntese da tanase mesmo quando a única fonte de carbono foi a glicose. Com isto diferentes autores, incluindo LEKHA e LONSANE (1997), têm afirmado que a tanase produzida por espécies de Aspergillus seria livre de repressão catabólica. Em discordância aos demais, PINTO (2003) observou repressão na síntese da enzima por $A$. niger 3T5B8 em meios submerso e semi-sólido, quando ocorreu a adição de glicose. Para as espécies do gênero Penicillium dados disponíveis são insuficientes para confirmar ou negar essa suposição.

LEKHA e LONSANE (1997), em sua revisão, comentaram que nenhum artigo sobre inibição por produto final em tanase foi publicado.

BRADOO, GUPTA e SAXENA (1996) observaram que a adição de ácido gálico em meios líquidos contendo ácido tânico e glicose promovia total inibição na síntese de tanase em $A$. japonicus. Também não foi observada a produção da enzima por $A$. niger Aa-20 em fermentação submersa, quando o ácido gálico foi utilizado como única fonte de carbono (AGUILAR et la., 2001). Ambos os artigos sugerem que o ácido gálico atua como repressor de síntese. Esse fato se contrapõe ao observado por KNUDSON (1913) em fermentação submersa, na qual o ácido gálico desempenha papel de indutor.

\section{CARACTERÍSTICAS E PROPRIEDADES DA TANASE}

A tanase apresenta pH ótimo em torno de 5,5. Sua estabilidade em diferentes valores de $\mathrm{pH}$ pode variar entre faixas estreitas $(5,0$ a 5,5$)$ e largas $(3,5$ a 8,0), dependendo da fonte de obtenção da enzima (Tabela 2). SHARMA et al. (1999) observaram pH ótimo da tanase de 6,0 com pico secundário em 4,5. HASLAM e TANNER (1970) também relataram fato similar, sendo verificados dois valores de $\mathrm{pH}$ ótimo $(4,2$ e 4,8$)$ para a tanase de $A$. niger 106. Em ambos os trabalhos, esse fato foi atribuído à dupla especificidade de ação da tanase. Um dos valores corresponderia a ótima atividade esterásica enquanto o outro corresponderia a atividade 
depsidásica. A temperatura ótima para atividade desta enzima ocorre, em geral, próxima a $35^{\circ} \mathrm{C}$. Contudo, temperaturas mais elevadas $(50,60$ e $70^{\circ} \mathrm{C}$ ) foram observadas para tanases produzidas por $A$. flavus IFO 5839, Candida sp. K 16 e A. niger N888 (Tabela 2).

A estabilidade da tanase ao $\mathrm{pH}$ ocorre em largas faixas para várias linhagens microbianas. Entretanto, as tanases produzidas por $A$. flavus IFO 5839, A. niger AN11 e $P$. chrysogenum enquadraram-se em faixas bem mais estreitas (5,0 a 5,5; 5,0 a 6,5 e 4,5 a 6,0, respectivamente). Para a temperatura, a estabilidade da tanase ocorre basicamente entre 10 e $45^{\circ} \mathrm{C}$ (Tabela 2 ).

As tanases produzidas por fungos filamentosos e leveduras são, na maioria, estruturas protéicas com elevada massa molecular, podendo ser superiores a $300 \mathrm{KDa}$ (Tabela 2). A enzima nativa parece ser constituída de duas subunidades idênticas e mesma massa molecular (AOKI, SHINKE e NISHIRA, 1976; RAJKUMAR e NANDY, 1983). Em contrapartida, BHARDWAl et al. (2003) observaram duas cadeias polipeptídicas distintas, tanto para a enzima produzida por $A$. niger MTCC2425 (102 e $83 \mathrm{KDa}$ ), quanto para a enzima produzida pela Kikkoman Co, Japão (87 e 56 KDa). Para HATAMOTO et al. (1996), o gene que codifica a tanase é transcrito como uma única cadeia polipeptídica clivada por modificação pós-transcrição em duas pequenas subunidades distintas, com 33 e $30 \mathrm{KDa}$, unidas por ligações dissulfeto. Afirmaram que a tanase nativa consiste em quatro pares de subunidades, formando um heterooctâmero com peso molecular de $300 \mathrm{KDa}$. A tanase de $A$. oryzae, expressa em Pichia pastoris, é formada por um par de subunidades distintas (31 e $34 \mathrm{KDa}$ ), também unidas por ligações dissulfeto e massa molecular total de $100 \mathrm{KDa}$ (ZHONG et al., 2004). SKENE e BROOKER (1995) evidenciaram que a molécula de tanase produzida por Selenomonas ruminantium apresenta baixo peso molecular ( $59 \mathrm{KDa}$ ), sendo composta por apenas uma cadeia polipeptídica.

Todas as tanases fúngicas são caracterizadas como glicoproteínas. 0 conteúdo de carboidratos pode variar de 25,4 a $66,2 \%$ do peso total da enzima (YAMADA et al., 1968; AOKI, SHINKE e NISHIRA, 1976a; RAJKUMAR E NANDY, 1983 BARTHOMEUF, REGERAT e POURRAT, 1994; HATAMOTO et al., 1996; ZHONG et al., 2004). O papel exato desses elevados conteúdos de carboidratos não é conhecido. Suspeitase que seja a maneira de proteger o núcleo protéico da ação desnaturante dos taninos hidrolizáveis e de direcionar o substrato ao centro ativo da enzima para possibilitar a quebra desse em seus respectivos componentes, glicose e ácido gálico (LEKHA e LONSANE, 1997). 


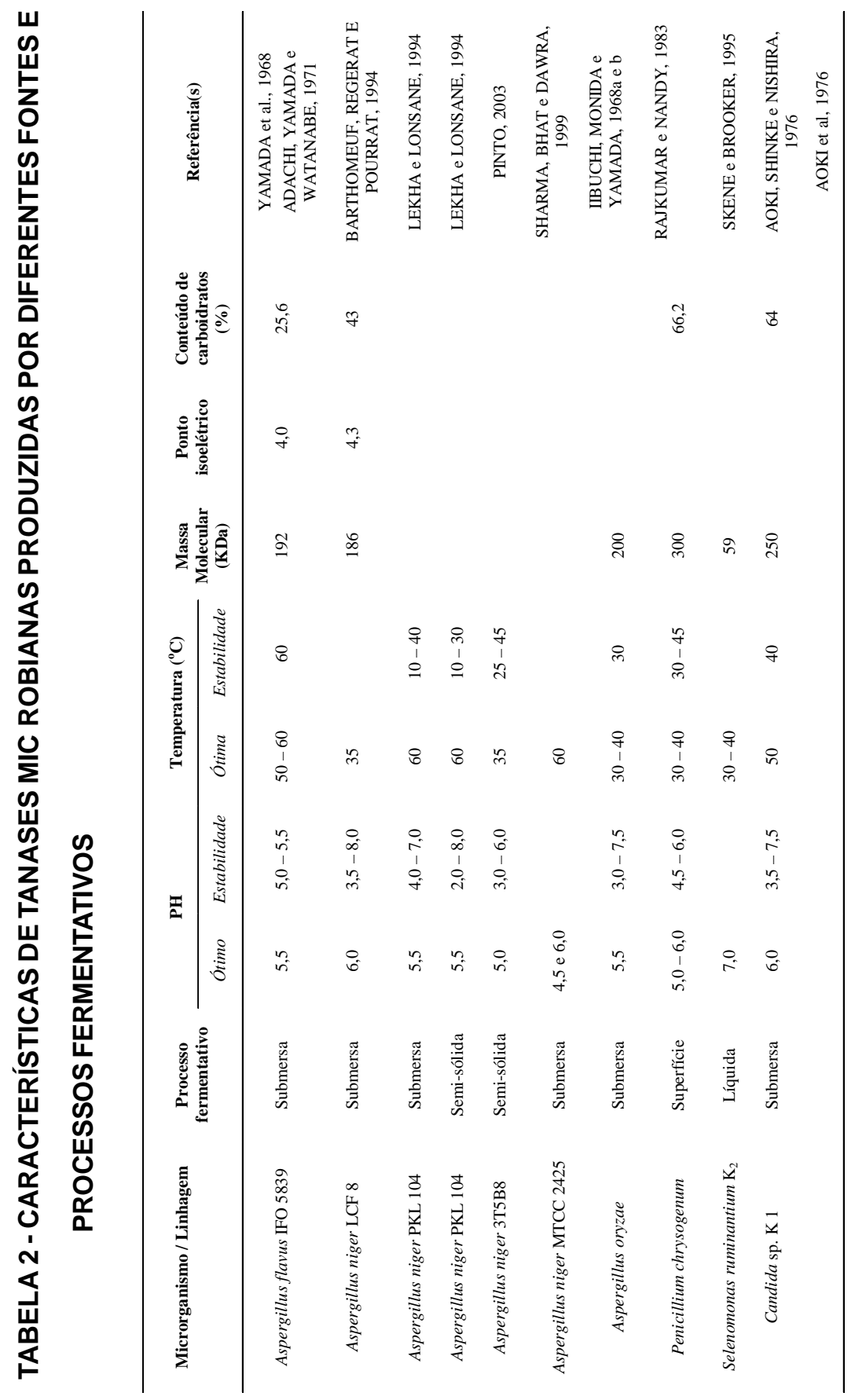


Diferentes substâncias, como o-fenantrolina, PMSF, EDTA, 2mercaptoetanol, etileno diamina e tioglicolato de sódio têm se mostrado potentes inativadores da tanase. Já DFP e diferentes íons metálicos, como $\mathrm{Cu}^{2+}, \mathrm{Zn}^{2+}, \mathrm{Fe}^{3+}, \mathrm{Mn}^{2+}$ e $\mathrm{Mg}^{2+}$ têm se apresentado como inibidores da atividade (BARTHOMEUF, REGERAT e POURRAT, 1994; IIBUCHI, MONIDA e YAMADA, 1967; AOKI, SHINKE e NISHIRA, 1976; BHARDWAJ, SINGH e BATH, 2003).

KAR, BANERJEE e BHATTACHARYYA (2003) observaram que 1,0 mM de $\mathrm{MgCl}_{2}, \mathrm{HgCl}, \mathrm{NaBr}$ e $\mathrm{Na}_{2} \mathrm{~S}_{2} \mathrm{O}_{3}$ ativaram a enzima em 138, 105, 220 e $164 \%$, respectivamente, em relação ao controle sem a presença de sais. A adição de Tween 40 e Tween 80 até 0,40 e 0,05\%, respectivamente, também aumentaram a atividade da enzima. Contudo, foi a presença do íon $\mathrm{NH}_{4}{ }^{+}$que mais afetou positivamente a tanase. $\mathrm{A}$ adição de $0,1 \%$ de $\mathrm{NH}_{4} \mathrm{Cl}$ à solução de ensaio aumentou em $401 \%$ a atividade da tanase. Todas as demais substâncias inibiram total ou parcialmente a enzima.

\section{IMOBILIZAÇÃO DA TANASE}

WEETAL e DETAR (1984) imobilizaram tanase covalentemente em derivado alquilamino de sílica porosa ativado com glutaraldeído. $\mathrm{O} \mathrm{pH}$ ótimo da enzima imobilizada apresentou pequeno aumento.

GAATHON, GROSS e ROZHANSKI (1989) imobilizaram tanase por armadilhamento em micelas reversas para a produção de propilgalato mediante transesterificação do ácido tânico em heptano. O sistema proposto (tanase, ácido tânico, propanol, água, íons tamponantes e surfactante) mostrou-se muito complexo.

NICOLAS et al. (1998) propuseram que a tanase imobilizada covalentemente em suportes insolúveis inorgânicos ou polímeros sintéticos seja utilizada no tratamento de extratos de chá. Nesse processo a enzima é ligada ao suporte por meio da sua fração glicosídica representando avanço no estado da arte, pois as tentativas anteriores de imobilização eram realizadas sobre a fração protéica (SANDERSON et al, 1977). Enquanto no processo anterior a enzima perdia a atividade após poucos ciclos de utilização, no descrito por NICOLAS et al. (1998) a enzima permanecia ativa após 400 ciclos. No mesmo curso de ação, SHARMA, BHAT e GUPTA (2002) imobilizaram a tanase de $A$. niger MTCC 2425 em matriz de Sepharose - Concanavalina A, sendo capazes de manter $97 \%$ da atividade total com aumento de $62 \%$ na 
atividade específica. As enzimas, livre e imobilizada apresentaram respostas similares à variação do $\mathrm{pH}$ do meio reacional. Após a imobilização, os valores de $\mathrm{K}_{\mathrm{M}}$ e $\mathrm{V}_{\mathrm{MAX}}$ sofreram aumentos de 0,3 para $0,6 \mathrm{mM}$ e de 0,013 para $0,020 \mu \mathrm{mol}$. $\mathrm{min}^{-1}$, respectivamente. A enzima imobilizada apresentou maior taxa de conversão do substrato testado (metilgalato) em ácido gálico, bem como alta estabilidade após 6 ciclos de utilização.

ABDEL-NABY et al. (1999) avaliaram a imobilização da tanase em diferentes suportes e vários métodos: adsorção física (alumina e quitina coloidal), ligação iônica (Dowex 50W e DEAE-Sephadex A-25), ligação covalente (quitina e quitosana) e por encapsulamento (poliacrilamida e alginato de cálcio). Dos métodos e suportes avaliados, a imobilização covalente em quitosana foi a que apresentou melhor rendimento (26,6\%). Também foi demonstrado que ocorrem as pequenas alterações nos valores de $\mathrm{pH}$ e temperatura ótimos, de 5,5 para 4,5 e de 40 para $55^{\circ} \mathrm{C}$, respectivamente.

\section{APLICAÇÕES DA TANASE}

\subsection{PREPARAÇÃO DE CHÁS INSTANTÂNEOS}

O chá é uma das bebidas mais consumidas no mundo, devido ao seu aroma, sabor e também pelos seus efeitos medicinais (KHOKHAR e MAGNUSDOTTIR, 2002). O processo de manufatura de chás consiste nas etapas de murchamento, maceração, fermentação e secagem. Basicamente há três tipos de chá: verde, sem fermentação; Oolong, parcialmente fermentado e preto, totalmente fermentado (SANDERSON et al., 1977 e BALENTINE et al., 2002).

A solubilidade em água fria constitui requisito fundamental para o chá instantâneo, pois são freqüentemente utilizados como chás gelados (SANDERSON et al, 1974). A presença de "creme" (precipitado insolúvel em água que se forma naturalmente em bebidas a base de chá a $4^{\circ} \mathrm{C}$ ou temperaturas inferiores e que pode permanecer por horas) é o principal problema de fabricação de chás instantâneos. O creme é o complexo de polifenóis poliméricos presentes nos chás (tearubiginas e teaflavinas) com a cafeína. No processo convencional de preparação do chá instantâneo, o extrato solúvel em água quente é resfriado sob agitação e centrifugado para a remoção do creme. O creme, usualmente descartado, representa considerável perda da maior parte dos componentes do sabor. 
O método químico para solubilização do creme envolve tratamentos com sulfito, oxigênio molecular e uma substância alcalina (SMITH, 1968; SANDERSON et al, 1974 e LEKHA e LONSANE, 1997). Muitos consumidores preferem não utilizar o pó de chá instantâneo pela percepção da redução do sabor, ou por considerá-la como bebida inferior (BALENTINE et al, 2002).

A tanase adicionada ao processo de manufatura, em diferentes etapas, catalisa a quebra das ligações éster nos galatos presentes nas folhas (Figura 3B). A adição da tanase promove diminuição da turbidez e aumento da extratibilidade de compostos fenólicos e de voláteis de modo que a bebida final (quente ou fria) apresente qualidade superior à obtida pelo processo de extração a quente (TAKINO, 1976; TSAI, 1987). Amostras tratadas com tanase podem apresentar redução de até $82 \%$ no teor de sólidos não-dissolvidos (LEKHA e LONSANE, 1997).

A tanase pode ser utilizada de forma isolada (SANDERSON et al., 1977; GOODSALL et al., 2002; BLAIR et al., 2003), ou combinada com outras enzimas (AGBO e SPRADLIN, 1995; LEHMBERG et al., 2000), substâncias químicas (LEHMBERG et al., 2000) ou zeólita (BARRETT et al., 1999).

\subsection{PRODUÇÃO DE COMPOSTOS ANTIOXIDANTES}

A auto-oxidação de lípidios em alimentos constitui preocupação de processadores e consumidores. O método comumente usado para inibir as reações de oxidação lipídica é a aplicação de antioxidantes sintéticos. Alimentos que devem ser estabilizados contra a oxidação são, por exemplo, óleos de fritura, gorduras, flocos de batata, produtos de panificação, emulsões cárneas, cereais pré-cozidos, leite de soja, produtos de frango, produtos emulsionados, pizza congelada, queijos e alimentos para animais (MAI, CHAMBERS e McDONALD, 1989).

Poucos compostos sintéticos são permitidos para adição em alimentos como, por exemplo, butilhidroxitolueno (BHT), butilhidroxianisol (BHA), propilgalato ( $\mathrm{PG}$ ) e $t$-butilhidroxiquinona (TBHQ). Mesmo esses antioxidantes estão sendo examinados por agências reguladoras e a pesquisa de antioxidantes de fontes naturais tem sido elevada. Produto natural com excelentes propriedades antioxidantes, o Rosemary AR tem como grande desvantagem o fato de conferir ao alimento sabor herbal característico muito intenso (MAI, CHAMBERS e McDONALD, 1990). 
MAI, CHAMBERS e McDONALD (1989 e 1990) descreveram os processos de obtenção de extratos de chá com propriedades antioxidantes pela presença de constituintes fenólicos como, ácido gálico, epicatequina, epigalocatequina, galato de epicatequina e galato de epigalocatequina. A tanase pode ser adicionada em diferentes fases do processo para aumentar a característica antioxidante em razão da maior liberação de ácido gálico nos extratos. Os extratos obtidos são incorporados aos alimentos suscetíveis à oxidação lipídica em proporções que variam de 0,005 a $1,5 \%$. Os autores também ressaltaram que os extratos apresentaram sinergismo antioxidante, quando combinados com ácido ascórbico ou com lecitina.

\subsection{FABRICAÇÃO DE BEBIDAS}

A tanase pode ser utilizada para reduzir a formação de turbidez em bebidas que contenham componentes fenólicos. A descoloração e desenvolvimento de turbidez da cerveja durante a estocagem pode ser evitada com a hidrólise dos polifenóis do malte com tanase e lactase (LEKHA e LONSANE, 1997). De modo similar, a utilização dessas duas enzimas para tratar o suco de uva para a remoção de substâncias fenólicas apresenta potencial para a estabilização de vinhos (CANTARELLI et al., 1989).

\subsection{ADITIVO PARA RAÇÃO ANIMAL}

O emprego de enzimas em rações torna possível aumentar a assimilação dos nutrientes contidos na formulação, facilitando a utilização de constituintes que o animal não poderia digerir fácil ou completamente. As enzimas possibilitam o uso de matérias-primas nobres (como cereais e sementes) de forma a se obter componentes de alta qualidade, sendo empregados particularmente em rações para animais jovens (MESCHONAT et al., 2001).

Os taninos apresentam efeitos antinutricionais bem documentados (SINGLETON e KRATZER, 1969), estando presentes em várias plantas utilizadas como ração animal (BATE-SMITH e RASPER, 1969). O uso da tanase em rações contendo taninos pode trazer efeitos benéficos na remoção desses compostos indesejáveis, aumentando a digestibilidade e favorecendo a assimilação (LEKHA e LONSANE, 1997). MESCHONAT et al. (2001) propuseram a incorporação de pregranulados enzimáticos estáveis com atividade de tanase à ração animal peletizada, individualmente ou combinada com outras enzimas (oxinitrilase, quitinase, 
queratinase, glicose oxidase, peroxidase, lisozima, muramidase, carbohidrases, proteases, lipases e esterases).

\subsection{PRODUÇÃO DE ÁCIDO GÁLICO}

O ácido gálico tem seu principal uso na indústria farmacêutica para a síntese de trimetoprima, agente antibacteriano normalmente empregado com a sulfonamida. Juntas as duas substâncias apresentam largo espectro de ação. $O$ ácido gálico também pode ser utilizado para a síntese de propilgalato ou pirogalol (KAR e BANERJEE, 2000). O ácido gálico é tradicionalmente obtido pela hidrólise ácida de galotaninos (LEKHA e LONSANE, 1997). Rotas biotecnológicas, baseadas na utilização de microrganismos viáveis isolados (POURRAT et al., 1985; KAR, BANERJEE e BHATTACHARYYA, 1999), ou em co-cultura (BANERJEE, MUKHERJEE e PATRI, 2005), ou tanase isolada (DESCHAMPS e LEBEAULT, 1984) têm sido propostas. Essas apresentariam elevada eficiência de conversão, bem como gerariam menos sub-produtos.

\subsection{PRODUÇÃO DE ÁCIDO ELÁGICO}

Ao contrário do ácido gálico, o ácido elágico (Figura 1C) não é completamente explorado em razão de seu elevado custo de produção. Galotaninos podem ser hidrolizados por ácidos, bases, enzimas e microrganismos. Os elagitaninos (pela sua estrutura complexa) dificilmente são hidrolizados por métodos tradicionais, devido à formação de subprodutos, o que dificulta o isolamento do produto de interesse. HUANG, NI e BORTHWICK (2005) propuseram o uso da linhagem $A$. niger SHL 6, identificada como produtora de tanase para a liberação/ acumulação de ácido elágico no meio de fermentação.

\subsection{SIINTESE DE ÉSTERES}

WEETALL (1984) avaliou a síntese de diferentes ésteres de ácido gálico por tanases livres e imobilizadas. No sistema de enzima livre, cujo solvente é o próprio álccol utilizado na reação, foi observada a síntese de metil e etilgalato com conversões de 40,1 e 17,9\%, respectivamente. Em contrapatida, com a enzima imobilizada foi verificada a síntese de propil $(41,4 \%)$ e amilgalato $(78,0 \%)$. A troca do solvente para hexano aparentemente permitiu maiores taxas de conversão que nos sistemas alcoólicos. Também relataram que a presença de água é desfavorável para a reação. Dentre os ésteres sintetizados por WEETALL (1984), o propilgalato despertou maior interesse por apresentar propriedades 
antioxidantes, sendo freqüentemente utilizado na indústria de alimentos (MAl et al., 1989).

WEETALL (1984) demonstrou que o ácido gálico representa $75 \%$ do custo de síntese de propilgalato. Desta forma, SHARMA e GUPTA (2003) utilizaram rota alternativa baseada na transesterificação do ácido tânico a propilgalato em $n$-propanol. As adições de água e sorbitol ao meio até $1 \%$ e $5 \mathrm{mmol} / \mathrm{g}$ de tanase, respectivamente, promoveram aumento no rendimento da reação. Em condições otimizadas foi obtido $86 \%$ de conversão do ácido tânico em propilgalato.

\subsection{TRATAMENTO DE EFLUENTES}

Efluentes de curtumes contém altas quantidades de polifenóis, que representam elevada carga poluente. A utilização de tanase pode constituir tratamento efetivo para esse tipo de efluente (AGUILAR e GUTIÉRREZSANCHES, 2001).

\section{CONCLUSÃO}

Muitas lacunas no conhecimento sobre a tanase ainda estão abertas, principalmente na regulação de sua síntese, sua estrutura, produção e aplicações. Relatos sobre os fenômenos de indução e repressão aparecem de forma pontual e, muitas vezes, contraditória. Constatou-se que ao contrário do senso comum não existem apenas duas isoformas de tanase, mas várias enzimas estruturalmente distintas, produzidas por diferentes linhagens microbianas. Desta forma, generalizações devem ser feitas de forma cautelosa. A fermentação semi-sólida tem sido apontada como a mais adequada para síntese de tanase, apesar das formulações comercialmente disponíveis terem sido obtidas pelo processo submerso. A principal aplicação dessa enzima encontra-se na produção de chás instantâneos, porém outros campos potenciais podem ser vislumbrados como sua utilização para elaboração de rações animais com maior valor nutricional, produção de compostos antioxidantes e produção de ácido gálico.

\footnotetext{
Abstract

TANNASE: CONCEPTS, PRODUCTION AND APPLICATION

The aim of this work was to review the tannase knowledge, pointing the needs and use perspectives, especially for the food area. Topics were emphasized such as
} 
tannase physiological importance and its action mechanism, its production by microorganisms, analytical methods for its determination, its production by fermentation, the biosynthesis regulation, its characteristics and properties, its immobilization and applications. The main application for this enzyme was in instant tea production; however other important fields may be explored, such as its use to produce animal feed with higher nutritional value, production of antioxidant compounds and gallic acid.

KEY-WORDS: TANNASE - PRODUCTION; FOOD INDUSTRY.

\section{REFERÊNCIAS}

1 ABDEL-NABY, M.A.; SHERIF, A.A.; EL-TANASH, A.B.; MANKARIOS, A.T. Immobilization of Aspergillus oryzae tannase and properties of the immobilized enzyme. Journal of Applied Microbiology, v. 87, n. 1, p. 108-114, 1999.

2 ADACHI, O.; YAMADA, H.; WATANABE, M. Studies on fungal tannase. 3. Inhibition of tannase by diisopropylfluorophosphate. Journal of Fermentation Technology, v. 49, n. 3, p. 230-234, 1971.

3 AGBO, F.; SPRADLIN, J.E. Enzymatic clarification of tea extracts. U.S. Patent 5.445.836. 1995.

4 AGUILAR, C.N.; AUGUR, C.; VINIEGRA-GONZÁLEZ, G.; FAVELA, E. A comparision of methods to determine tannin acyl hydrolase activity. Brazilian Archives of Biology and Tecnhnology, v. 42, n. 3, p. 355-361, 1999.

5 AGUILAR, C.N.; AUGUR, C.; FAVELA-TORRES, E.; VINIEGRA-GONZÁLEZ, G. Induction and repression patterns of fungal tannase in solid-state and submerged cultures. Process Biochememistry, v. 36, p. 565-570, 2001.

6 AGUILAR, C.N.; GUTIÉRREZ-SANCHES, G.; Review: sources, properties, applications and potential uses of tannin acyl hydrolases. Food Science Technology International, v. 7, n. 5, p. 373-382, 2001.

7 AJAY KUMAR, R.; GUNASEKARAN, P.; LAKSHMANAN, M. Biodegradation of tannic acid by Citrobacter freundii isolated from a tannery effluent. Journal of Basic Microbiology, v. 39, n. 3, p. 161-168, 1999.

8 AOKI, K.; SHINKE, R.; NISHIRA, H. Purification and some properties of yeast tannase. Agricultural and Biological Chemistry, v. 40, n. 1, p. 79-85, 1976.

9 BANERJEE, R.; MUKHERJEE, G.; PATRI, K.C. Microbial transformation of tanninrich substrate to gallic acid through co-culture method. Bioresource Technology, v. 96, p. 949-953, 2005.

10 BAJPAI, B.; PALTI, S. Tannin acyl hydrolase activity of Aspergillus, Penicillium, Fusarium and Trichoderma. World Journal of Microbiology and Biotechnology. v. 12, p. 217-220, 1996.

11 BALENTINE, D.A.; GOBBO, S.A.; HANG, R.S.; QI, X.; PARRY, A.D.; GOODSALL, C.W. Cold brew tea. U.S. Patent 6.491.961. 2002. 
13 BARTHOMEUF, C.; REGERAT, F.; POURRAT, H. Production, purification and characterization of a tannase from Aspergillus niger LCF8. Journal of Fermentation and Bioengineering, v. 77, n. 3, p. 320-323, 1994.

14 BATE-SMITH, E.C.; RASPER, V.J. Tannins of grain sorghum - Luteoforol (leucoluteolinidin), 3', 4, 4', 5, 7 - pentahydroxyflavan. Food Science, v. 34, p. 203-209, 1969.

15 BHARDWAJ, R.; SINGH, B.; BHAT, T.K. Purification and characterization of tannin acyl hydrolase from Aspergillus niger MTCC 2425. Journal of Basic Microbiology, v. 43, n. 6, p. 449-461, 2003.

16 BATRA, A.; SAXENA, R.K. Potential tannase producers from the genera Aspergillus and Penicillium. Process Biochemistry, v. 40, p. 1553-1557, 2005.

17 BEVERINI, M.; METCHE, M. Identification, purification and physicochemical properties of tannase of Aspergillus niger. Sciences des Alimentes. v. 10, p. 807-816, 1990.

18 BHAT, T.K.; SINGH, B.; SHARMA, O.P. Microbial degradation of tannins: a current perspective. Biodegradation, v. 9, p. 343-357, 1998.

19 BLAIR, R.L.; MAYAKA, R.O.; PARRY, A.D.; STABLER, P.J. Black tea manufacture. U.S. Patent 6.632.462. 2003.

20 BRADOO, S.; GUPTA, R.; SAXENA, R.K. Screening of extracellular tannase producing fungi: development of a rapid and simple plate assay. Journal of General and Applied Microbiology, v. 42, p. 325-329, 1996.

21 BRUYNE, T.D.; PIETERS, L.; DEELSTRA, H.; VLIETINCK, A. Condensed vegetable tannins: biodiversity in structure and biological activities. Biochemical and Systematic Ecology, v. 27, p. 445-459, 1999.

22 CANNAS, A. Tannins: fascinating but something dangerous molecules. Disponível em: http://www.ansci.cornell.edu/plants/toxicagents/tannins/ index.htm. Acesso em: 12 fev. 2002.

23 CANTARELLI, C.; BRENNA, O.; GIOVANELLI, G.; ROSSI, M. Beverage stabilization through enzymic removal of phenolics. Food Biochemistry, v. 3, n. 2, p. 203-213, 1989.

24 CHUNG, K.T.; LU, Z.; CHOU, M.W. Mechanism of inhibition of tannic acid related compounds on the growth of intestinal bacteria. Food Chemistry and Toxicology, v. 36, p. 1053-1060, 1998.

25 DESCHAMPS, A.M., OTUK, G., LEBEUALT, J.M. Production of tannase and degradation of chestnut tannins by bacteria. Fermentation Technology, v. 61, p. 55-59, 1983. 
26 DESCHAMPS, A.M.; LEBEAULT, J.M. Production of gallic acid from tara (Caesalpinia spinosa) tannin by bacterial strains. Biotecnology Letters, v. 6 n. 4 , p. 237-241, 1984.

27 DESCHAMPS, A.M.; LEULLIETTE, L. Tannins degradation by yeast from decaying barks. International Biodeterioration, v. 20, n. 4, p. 237-241, 1994.

28 DESHPANDE, S.S.; CHERYAN, M.; SALUNKHE, D.K. Tannin analysis of food products. CRC Critical Reviews in Food Science and Nutrition, v. 24, n. 4, p. 401-449, 1984.

29 DHAR, S.C., BOSE, A.M. Purification, crystallization and physico-chemical properties of tannase from Aspergillus niger. Leather Science, v. 11, p. 27-38, 1964.

30 GAATHON, A.; GROSS, Z.; ROZHANSKI, M.; Propyl gallate - Enzymatic synthesis in a reverse micelle system. Enzyme and Microbial Technology, v. 11, n. 9, p. 604-609, 1989.

31 GANGA, P.S.; NANDY, S.C.; SANTAPPA, M. Effect of environmental factors on the production of fungal tannase: Part I. Laether Science, v. 24. p. 8-16, 1977.

32 GARCIA-CONESA, M.T.; OSTERGAARD, P.; KAUPPINEN, S.; WILLIANSON, G. Hydrolisis of diethyl diferulates by a tannase from Aspergillus oryzae. Carbohydrate Polymers, v. 44, p. 319-324. 2001.

33 HASLAM, E.; LILLEY, T.H. Natural astringency in foodstuffs: a molecular interpretation. CRC Critical Reviews in Food Science and Nutrition, v. 27, n. 1, p. 1-40, 1988.

34 HASLAM, E.; STANGROOM, J.E. The esterase and depsidase activities of tannase. Biochemical Journal, v. 99, p. 28-31, 1966.

35 HASLAM, E.; TANNER, R. Spectrophotometric assay of tannase. Phytochemistry, v. 90, p. 2305-2309, 1970.

36 HATAMOTO, O.; WATARAI, T.; KIKUCHI, M.; MIZUSAWA, K.; SEKINE, H. Cloning and sequencing of the gene encoding tannase and a structural study of the tannase subunit from Aspergillus oryzae. Gene, v. 175, n. 1-2, p. 215-221, 1996.

37 HUANG, W.; NI, J.; BORTHWICK, A.G.L. Biosynthesis of valonia tannin hydrolase and hydrolysis of valonia tannin to ellagic acid by Aspergillus SHL 6. Process Biochemistry, v. 40, p. 1245-1249, 2005.

38 IIBUCHI, S.; MONIDA, Y.; YAMADA, K. Studies on tannin acyl hydrolase of microorganisms. Part II. A new method determining the enzyme activity using the change of ultra violet absorption. Agricultural and Biological Chemistry, v. 31, p. 513-518, 1968a.

39 IIBUCHI, S.; MONIDA, Y.; YAMADA, K. Studies on tannin acyl hydrolase of 
microorganisms. Part III. Purification of enzyme and some properties of it. Agricultural and Biological Chemistry, v. 32, p. 803-809, 1968b.

40 INOUE, K.H.; HAGERMAN, A.E. Determination of gallotannin with rhodanine. Analytical Biochemistry, v. 169, p. 363-369, 1988.

41 JEAN, D.; POURRAT, H.; POURRAT A.; CARNAT, A. Assay of tannase (tannin acylhydrolase EC 3.1.1.20) by gas chromatography. Analytical Biochemistry, v. 110, p. 369-372, 1981.

42 KAR, B.; BANERJEE, R. Biosynthesis of tannin acyl hydrolase from tanninrich forest residue under different fermentation conditions. Journal of Industrial Microbiology and Biotechnology, v. 25, p. 29-38, 2000.

43 KAR, B.; BANERJEE, R.; BHATTACHARYYA, B.C. Microbial production of gallic acid by modified solid state fermentation. Journal of Industrial Microbiology and Biotechnology, v. 23, p. 173-177, 1999.

44 KAR, B.; BANERJEE, R.; BHATTACHARYYA, B.C. Effect of additives on the behavioural properties of tannin acyl hydrolase. Process Biochemistry, v. 38, p. 1285-1293, 2003.

45 KHOKHAR, S., MAGNUSDOTTIR, S.G.M. Totalotal phenol, catechin, and caffeine contents of teas commonly consumed in the United Kingdom. Journal of Agricultural and Food Chemistry, v. 50, n. 3, p. 565-570, 2002.

46 KNUDSON, L. Tannic acid fermentation. Journal of Biological Chemistry, v. 14, n. 3, p. 159-184, 1913.

47 LAGEMAAT, J.V.; PYLE, D.L. Solid-state fermentation and bioremediation: development of a continuous process for the production of fungal tannase. Chemical Engineering Journal, v. 84, p. 115-123, 2001.

48 LEHMBERG, G.L.; MA, S.X. Tea concentrate prepared by enzymatic extraction and containing xanthan gum which is stable at ambient temperature. U.S. Patent 6.024.991. 2000.

49 LEKHA, P.K.; LONSANE, B.K. Comparative titres, location and properties of tannin acyl hydrolase produced by Aspergillus niger PKL104 in solid-state, liquid surface and submerged fermentations. Process Biochemistry, v. 29, n. 6, p. 497-503, 1994.

50 LEKHA, P.K.; LONSANE, B.K. Production and application of tannin acyl hydrolase: state of the art. Advances in Applied Microbiology, v. 44, p. 215-260, 1997.

51 LEKHA, P.K.; RAMAKRISHNA, M.; LONSANE, B.K. Strategies for isolation of potent cultures capable of producing tannin acyl hydrolase in high titres. Chemie, Microbiologie, Technologie, Lebensmittel, v. 15, n. 12, p. 510, 1993.

52 LIPPITSCH, M. Untersuchungen uber tannase bei Aspergillus niger. Archiv fur Mikrobiologie, v. 39, n. 3, p. 209-213, 1961. 
53 MAI, J.; CHAMBERS, L.J.; McDONALD, R.E. Antioxidant compositions. U.S. Patent 4.839.187. 1989.

54 MAI, J.; CHAMBERS, L.J.; McDONALD, R.E. Process for inhibiting lipid oxidation in food and composition thereby. U.S. Patent 4.925.681. 1990.

55 McLEOD, M.N. Plant tannins: their role in forage quality. Nutrition Abstract Reviews, v. 44, p. 803-815, 1974.

56 McSWEENEY, C.S.; PALMER, B.; McNEILL, D.M.; KRUASE, D.O. Microbial interactions with tannins: nutritional consequences for ruminants. Animal Feed Science and Technology, v. 91, p. 83-93, 2001.

57 MESCHONAT, B.; HERRMANN, H.A.; SPANNAGEL, R. SANDER, V.; KONIECZNY-JANDA, G.; SOMMER, M. Enzyme pre-granules for granular fodder. U.S. Patent 6.221.406. 2001.

58 MONDAL, K.C.; PATI, B.R. Studies on the extracellular tannase from newly isolated Bacillus licheniformis KBR 6. Journal of Basic Microbiology, v. 4, p. 223-232, 2000.

59 MUELLER-HARVEY, I.; REED, J.D. Identification of phenolic-compounds and their relationships to invitro digestibility of sorghum leaves from bird-resistant and non bird-resistant varieties. Journal of the Science of Food and Agriculture, v. 60, n. 2, p. 179-196, 1992.

60 NELSON, K.E.; PELL, A.N.; SCHOFIELD, P.; ZINDER, S. Isolation and characterization of an anaerobic ruminal bacteria capable of degrading hydrolyzable tannins. Applied and Environmental Microbiology. v. 61, n. 9, p. 3293-3298, 1995.

61 NEMOTO, K.; OSAWA, R.; HIROTA, K.; ONO, T.; MIYAKE, Y. An investigation of gram-negative tannin-protein complex degrading bacteria in fecal flora of various mammals. Journal of Veterinary Medical Science, v. 57, n. 5, p. 921-926, 1995.

62 NICOLAS, P.; RAETZ, E.; REYMOND, S.; SAUVAGEAT, J.L. Tea extract preparation. U.S. Patent 5.820.901. 1998.

63 NICOLSON, W.N.; NIERENSTEIN, M.; POOL, J.C. PRINCE, N.V. The action of tannase on gallotannin. Biochemical Journal, v. 25, p. 752-757, 1931.

64 NIEHAUS, J.U.; GROSS, G.G. A gallotannin degrading esterase from leaves of pendunculate oak. Phytochemistry, v. 45, p. 1555-1560, 1997.

65 NISHITANI, Y.; OSAWA, R. A novel colorimetric method to quantify tannase activity of viable bacteria. Journal of Microbiology Methods, v. 54, p. 281-284, 2003.

66 NISHITANI, Y.; SASAKI, E.; FUJISAWA, T.; OSAWA, R. Genotypic analyses of Lactobacilli with a range of tannase activities isolated from human feces 
and fermented foods. Systematic and Applied Microbiology, v. 27, p. 109-117, 2004.

67 OSAWA, R.; KUROISO, K.; GOTO, S.; SHIMIZU, A. Isolation of tannin-degrading Lactobacilli from humans and fermented foods. Applied Environmental Microbiology, v. 66, n. 7, p. 3093-3097, 2000.

68 PINTO, G.A.S. Produção de tanase por Aspergillus niger. Rio de Janeiro, 2003. 208 p. Tese (Doutorado - Tecnologia de Processos Químicos e Bioquímicos), Escola de Química, Universidade Federal do Rio de Janeiro.

69 PINTO, G.A.S.; LEITE, S.G.F.; TERZI, S.C.; COURI, S. Selection of tannaseproducing Aspergillus niger strains. Brazilian Journal of Microbiology, v. 32, p. 24-26, 2001.

70 POURRAT, H., REGERAT, F.; POURRAT, A.; JEAN, D. Production of tannase (tannin acyl hydrolase E.C. 3.1.1.20) by a strain of Aspergillus niger. Biotechnology Letters, v. 4, n. 9. p. 583-588, 1982.

71 POURRAT, H.; REGERAT, F.; POURRAT, A.; JEAN, D.J. Production of gallic acid from tara tannin by a strain of $A$. niger. Journal of Fermentation Technology, v. 63, n. 4, p. 401-403, 1985.

72 RAJKUMAR, S.; NANDY, S.C. Isolation, purification, and some properties of Penicillium chrysogenum tannase. Applied Environmental Microbiology, v. 46, n. 2, p. 525-527, 1983.

73 SANDERSON, G.W.; ENGLEWOOD, N.J., COGGON, P., ORANGEBURG, N.Y. Green tea conversion using tannase and natural tea enzyme. U.S. Patent. 3.812.266. 1974.

74 SANDERSON, G.W.; HOEFLER, A.G.; GRAHAM, H.N.; COGGON, P. Cold water extractable tea leaf and process. U.S. Patent 4.051.264. 1977.

75 SASAKI, E.; SHIMADA, T.; OSAWA, R.; NISHITANI, Y.; SPRING, S. Isolation of tannin-degrading bacteria isolated from feces of the Japanese large wood mouse, Apodemus speciosus, feeding on tannin-rich acorns. Systematic and Applied Microbiology, v. 28, n. 4, p. 358-365, 2005.

76 SCALBERT, A. Antimicrobial properties of tannins. Phytochemistry, v. 30, n. 12, p. 3875-3883, 1991.

77 SETH, M.; CHAND, S. Biosynthesis of tannase and hydrolysis of tannins to gallic acid by Aspergillus awamori - optimization of process parameters. Process Biochemistry, v. 36, p. 39-44, 2000.

78 SHARMA, S.; BHAT, T.K.; DAWRA, R.K. A spectrophotometric method for assay of tannase using rhodanine. Analytical Biochemistry, v. 279, p. 8589, 2000.

79 SHARMA, S.; BHAT, T.K.; DAWRA, R.K. Isolation, purification and properties of tannase from Aspergillus niger van Tieghem. World Journal of Microbiology and Biotechnology, v. 15, n. 6, p. 673-677, 1999. 
80 SHARMA, S.; BHAT, T.K.; GUPTA, M.N. Bioaffinity immobilization of tannase from Aspergillus niger on concanavalin A - Sepharose CL-4B. Biotechnology and Applied Biochemistry, v. 35, p. 165-169, 2002.

81 SHARMA, S.; GUPTA, M.N. Synthesis of antioxidant propyl gallate using tannase from Aspergillus niger van Teighem in nonaqueous media. Bioorganic Medicinal Chemical Letters, v. 13, p. 395-397, 2003.

82 SINGH, A.; HAYASHI, K. Microbialcellulase-protein architecture, molecularproperties and biosynthesis. Advances in Applied Microbiology; v. 40, p. 1-44, 1995.

83 SINGLETON, V.L.; KRATZER, F.H. J. Toxicity and related physiological activity of phenolic substances of plant origin. Agricultural and Food Chemistry, v. 17, p. $497-512,1969$.

84 SKENE, I.D.; BROOKER, J.D. Characterization of tannin acylhydrolase activity in the ruminal bacterium Selenomonas ruminantium. Anaerobe, v. 1, n. 6, p. 321-327. 1995.

85 SMITH, R.F. Studies on the formation and composition of "cream" in tea infusions. Journal of Science of Food and Agriculture, v. 19, p. 530534, 1968.

86 TAKINO, Y. Enzymatic solubilization of tea cream. U.S. Patent 3.959.497. 1976.

87 TEWARI, Y.B.; SCHANTZ, M.M.; REKHARSKY, M.V.; GOLDBERG R.N. Thermodynamics of hydrolysis of 3,4,5-trihydroxybenzoic acid propyl ester (n-propylgallate) to 3,4,5-trihydroxybenzoic acid (gallic acid) and propan-1ol in aqueous media and in toluene. Journal of Chemical Thermodynamics, v. 28, p. 171-185, 1996.

88 THIES, M.; FISCHER, R. Photometrische bestimmug von gallassäuredurch farbreaktion mit rhodanine. Mikrochimica Acta, v. 5, p. 809-814, 1973.

89 TSAI, C.H. Enzymatic treatment of black tea leaf. U.S. Patent 4.639.375. 1987.

90 VAQUERO, I.; MARCOBAL, A.; MUÑOZ, R. Tannase activity by lactic acid bacteria isolated from grape must and wine. International Journal of Food Microbiology, v. 96, p. 199-204, 2004.

91 WEETALL, H.H. Enzymatic gallic acid esterification. Biotechnology and Bioengineering, v. 27, p. 124-127, 1984.

92 YAMADA, H.; ADACHI, O.; WATANABE, M.; SATO, N. Studies of fungal tannase. Part I. Formation, purification and catalytic properties of tannase of Aspergillus flavus. Agricultural and Biological Chemistry, v. 32, n. 9, p. 1070-1978, 1968.

93 ZHONG, X. et al. Secretion, purification, and characterization of a recombinant Aspergillus oryzae tannase in Pichia pastoris. Protein Expression and Purification, v. 36, p. 165-169, 2004. 